\title{
An Empirical Study on Smartphone Addiction of the University Students
}

\author{
https://doi.org/10.3991/ijim.v13i12.11120 \\ Abdulmohsin Suliman Alkhunaizan \\ Majmaah University, Majmaah, Saudi Arabia \\ a.alkhunaizan@mu.edu.sa
}

\begin{abstract}
Smartphones have become an import part of the human life from the beginning of the 21 st century. Most of the people of different ages are using most modern smartphones. The present study is an attempt to examine the university students' smartphone addiction and their perception on its usefulness for the academic purposes. The study employed quantitative method to measure the smartphones addiction. Two questionnaires were used to gather the data for the present attempt. One questionnaire was used to gather the data for smartphone addition and the second questionnaire was used to attain learners' perception on the smartphone addiction for the learning purposes. The participants of the present attempt were $(\mathrm{N}=174)$ undergraduate students of a public university. The finding of the study displayed that university students spend more than 8 hours in a day on their smartphones. Findings also indicate that participants are aware of the positive aspects of smartphones. The study also recommends suggestion on the future research.
\end{abstract}

Keywords-Mobile phone, technology, addiction

\section{Introduction}

Nowadays the life of human beings is greatly dependent and associated with up-to date ubiquitous technology. The development of technology is a continuous process and it has changed the way we live, we buy things, act, work, travel, communication, and learning and teaching, interact, medical treatment and many other modes of life (Comer, 2018). The rapid advancement in the arena of technology has affected the life of common men to philosophers (Postman, 2011). In the past, the development of the technological gadgets and software has been definite. The technology is widespread that there were 1.5 trillion digital interactions in the year 2012. This entails that the digital technology, digital communication is present in all over the world and technological devices have become the integral part of our lives. More than $95 \%$ of the Saudi population has the fast and rapid access to the internet (Alshehri \& Meziane2017). Computers, laptops and tabs are the important elements of every family and everyone in the family has smartphones.

Mobile phone addiction or smartphone addiction is referred to an obsessive overuse of mobile phone devices (Kim et al. 2014). The availability of modern technolo- 
gies, including smartphones, made it conceivable that online activities are far and wide for education, communication, work, business or in general public use. The people in Saudi Arabia are using internet between 5 to 6 hours averagely. Smartphone usage trend in digital environment is increasing gradually. According to the report of General Authority for Statistics (GASTAT, 2018) the mobile phone usage has reached $99.17 \%$ in the year 2018. This means that almost everyone in the country is using mobile phone. The use of internet is $89.7 \%$ among the GASTAT survey participants. The use of internet through mobile is more common in the country especially among youth. GASTAT revealed that $68.9 \%$ of the population is using internet through smartphones. These figures could be the result of habits or addition of mobile phone usage.

Studies on the internet usage behavior found differences in the utilization of the internet activities (Muller et al, 2016; Weintein et al, 2015; Junco, 2015). These differences vary and when it comes to the students, the usage of the mobile phones and internet may be inclined to the learning purposes with socializing. Currently the people are more addicted to the smartphones and it is considered as the key problem (Kwon et al., 2013). According to Arab Newspaper report (dated 3rd May, 2019) revealed that young children are spending more time on the internet in their daily life. The reason is that smartphone users have the access to the entertainment and information content anywhere and anytime. This could take them to the addition of using their smartphones. The free large number of the applications of the smartphone attracts the attention of the students and general public in using them frequently. According to (Mcluhan, 1964) smartphone devices are the annexes of the human beings and these are different for other technological gadgets.

\section{Literature Review}

Smartphones have inimitable features, such as ubiquity, flexibility, size, screen size, display and applications that can be utilized anywhere anytime with the access to the data (Elhai, \& Hall, 2017; Papadakis \& Kalogiannakis, 2017). Due to its portability it allows users to interact with different applications and with other people 24/7. Most of the smartphones applications are useful for the educational pursuits also. The use of social media like Facebook, Twitter, and WhatsApp has the dual benefit. Many researcher (Shahbaz and Khan, 2017: Khan et al; 2018; Taj et al: 2016) have utilized WhatsApp teaching vocabulary to the young adults. In the 21 st century, life without a mobile phone device is unimaginable; thus, they are more dependent on the internet and smartphones (Wang\& Fesenmaier, 2016).

The utility of the smartphones greatly relies on the availability of the internet. In other words smartphone addiction is the internet addition. Internet addiction is "an impulse-control disorder with no involvement of an intoxicant; therefore, it is akin to pathological gambling" (Wang et al, 2013). He further illustrated that the smart phone or mobile phone addiction is directly associated to the addiction of the internet because of the similar features. The use of internet and smartphones is an undesirable activity which is associated with certain habits; such as sms, chat, using social media 
apps and interaction through call. Now people even do not turn off their cell phone and internet connection even if they are sleeping. They are using smartphones for business, socializing and even for stress relieve.

Cell phones and other portable advanced gadgets, for example, tablets, can be astonishing valuable educational assets for face to face, online and distance learning from school to postgraduate learners. They may, besides, be utilized as an instrument helpful for instructive and individual communication, cultivating connections between learners and their teachers (Oulasvirta, Wahlström, and Ericsson, 2011; UNESCO, 2013; Papadakis, 2018). Learners experience the advanced and digital experience in an exceptionally advanced environment through a wide assortment of cell phones (i.e., cell phones and tablets) those which can be utilized and changed over into collective learning rehearse. Cell phones are progressively winding up ever-present, entering and changing regular social practices and space. These practices can be supplemented with content reports in various organizations, varying media substance with smaller than normal recordings, small scale blogging applications, and interpersonal organizations (Twitter, Facebook, Linkedin, and so on.). Cell phones are no longer just an apparatus for communication, yet much of the time have turned into an instrument of individuals' social and work life, and conceivably, an amazing instrument in scholastic life. Subsequently, auxiliary and advanced educations in developing and developed nations are currently attempting to implement the utilization of cell phones in the institutions for teaching and learning from varied instruction method. (Johnson et al., 2014; UNESCO, 2013; Papadakis et al, 2017).

Though the smartphone is a handheld device and of the most of the learners keep phones with them in the class, research examining its addiction is limited. SánchezMartínez and Otero (2009) carried out a research study in the combination of selfreported monthly smartphone usage and its data in public high school in Spain. The findings of the study revealed that cellphone usage was negatively correlated with the learner academic results. Jacobsen and Forste (2011) rationalize the operations of cellphones with the performance of learners. The results also exhibited positive effects of the use of calls and messages. The study of (Junco and Cotton 2012) found that the college students consume more time (420 min) every day on the utilization of Information and Communication Technology (ICT). Moreover, Shahbaz and Khan (2017) used WhatsApp application to teach learners vocabulary with the formal classrooms in Saudi Arabia. The learners received vocabulary items through WhatsApp application. The finding of the study revealed the learners who used smartphones for learning vocabulary outperformed the learners who didn't. Similarly the findings of the Khan et al, (2018) showed positive perceptions of the learners and teachers on the implemental of m-learning and internet.

Modern smartphones allow consumers to access a diversity of applications and electronic media without any time constraints. Widespread activities such as chatting, video games, surfing the Internet, checking social media and video calls are currently inbuilt in the smartphones. Scholars have linked these applications for sending and receiving study material and learning activities to the learners. Several studies have indicated that the learners frequently indicate using smartphone application in class, doing homework and group discussion (Jacobsen and Forste, 2011; Shabaz and Khan, 
2017; Sánchez-Martínez and Otero, 2009; Kalogiannakis \& Papadakis, 2019). The review of literature suggest that smartphone based activities can develop learners' learning process if they are used planned carefully. Thus the education planner and instructors can use smartphone additions for positive aspects of learning.

\subsection{Theoretical background}

Research indicates that adults are addicted towards their handheld technology (Bright et al. 2015). The literature has limited investigation on the compulsion of technology except internet and gaming addiction. The numbers of the investigations had been made to evaluate the excessive usage of mobile phones and the time spent on the various applications on the internet (Wang et al, 2013; Khan et al. 2019; Müller et al, 2016: Lain and Houng; 2015; Ahmed \& Perji, 2011; Shambare \& Zhowa, 2012; Chen \& Nath, 2016). One illustration of the addiction is "compulsive activity involving excessive use, Withdrawal and negative repercussions" that stems from the excessive use of internet by the means of mobile phones (Kapahi et al. 2013). The present investigation adopts the grounded theory model of mobile technology which was proposed by Shiau, \& George (2014).

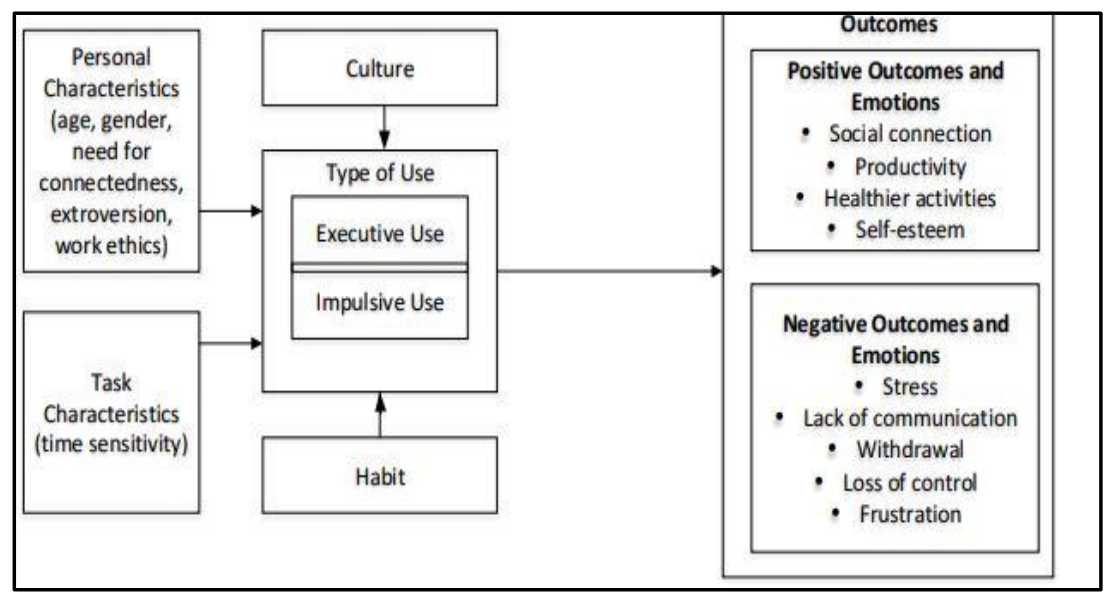

Fig. 1. Grounded theory model adopted from Shiau, \& George2014.

This mobile phone of technology addiction leads to uncover the distinctive and key elements of the person and responsibilities that appears to affect the individuals to reach at the impetuous or habitual use of mobile phone technologies. The model also refers to the positive role of culture that can influence the impact of mobile phone usage. The following model can be used to decrease the negative effect of smartphone addiction. 


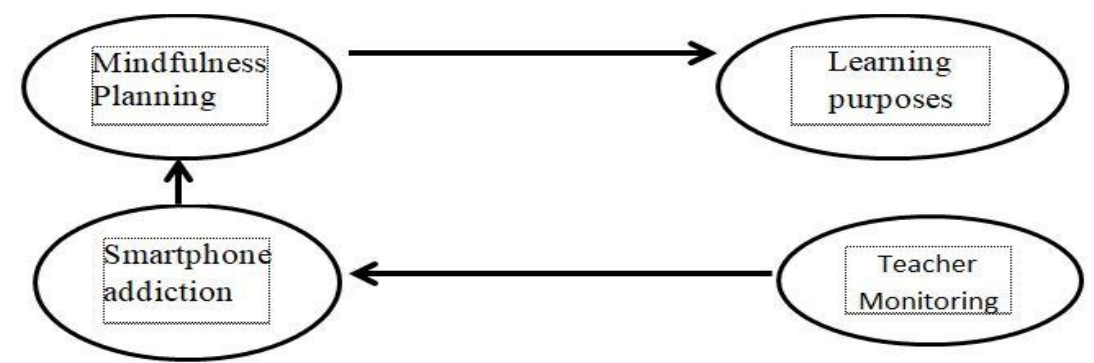

Fig. 2. Mobile addiction for learning purposes

\section{Research Questions}

The present attempt is governed by the following research questions:

- What are the associated activities of smartphones related to learners' smartphone addiction?

- What are the learners' perceptions on the smartphone addiction for learning purposes?

\section{$4 \quad$ Methodology}

The present study applied survey method to attain the data. A survey method helps researcher to gather the empirical data efficiently. Survey method is useful way of "questioning individuals on a topic or topics and then describing their responses" (Jackson, 2011. The study is primarily quantitative in nature. Two questionnaires were used to collect the data for the present study. One questionnaire was used to gather the data for smartphones addition and the second questionnaire was use to attain learners perception on the smartphone addiction for the learning purposes. For both questionnaires Google forms were created and sent to the participants through email, WhatsApp group and Facebook. The segments of the questionnaire were selected the basis of the usage of smartphone applications used in the region. The data from the Google form was code to numbers and then transformed to SPSS for the data analysis.

\subsection{Participants}

Data was gathered through a self-report questionnaire using Google forms. The participants of the present attempt were $(\mathrm{N}=174)$ undergraduate students of a public university. Initially the survey was sent to 205 students and 174 students completed the survey. Their age ranged between 19 to 25 years. 99 of the participants were male and 75 were female. They were given 10 days to complete the survey. The average time to complete the survey was estimated between 9 to 14 minutes. 


\subsection{Procedure}

To calculate the smartphone addiction, the items for the present study were adopted form (Roberts et al, 2014) and modified to the context. Twenty-five single items were used to measure how much time participants of the study devote in each of the smartphones activities of their interest including; calling, SMS, e-mail, Internet surfing, camera use, banking, calculator using, Calendar use, Holy Quran, WhatsApp, Twitter, YouTube, Soul Application, Azan Timing, Quibble Direction, Facebook, playing games, Instrgram, Weather, clock, News, Google maps, Shopping, live sports, and transport application etc. These smartphone activities were chosen on the basis of classroom discussion, familiarity of the applications in general public, cultural needs and review of mobile phone usage.

\section{$5 \quad$ Results}

The present study aims to investigate participants' smartphone addiction. The participants were asked to indicate their response on the selected 25 items which are linked with smartphone usage. T-test was employed to gauge the amount of time spent on the mobile phone activities. The comparison of male and female participants was also calculated in the engagement of smartphone activities. Table 1 illustrates the daily smartphone addiction of university students.

Table 1. Daily smartphone addiction of university students

\begin{tabular}{|l|c|c|c|c|c|c|}
\hline \multirow{2}{*}{ Smartphone activities } & \multicolumn{2}{|c|}{ Total Participants } & \multicolumn{2}{c|}{ Males } & \multicolumn{2}{c|}{ Females } \\
\cline { 2 - 7 } & Mean & SD & Mean & SD & Mean & SD \\
\hline Calls & 34.2 & 37.1 & 30.1 & 33.9 & 36.2 & 38.9 \\
\hline SMS & 91.3 & 63.2 & 83.8 & 60.1 & 99.1 & 70.3 \\
\hline Email & 49.1 & 47.2 & 41.1 & 37.2 & 56.3 & 54.9 \\
\hline Internet Surfing & 55.2 & 53.3 & 50.1 & 48.1 & 60.3 & 58.2 \\
\hline Camera Use & 46.2 & 44.9 & 31.6 & 30.1 & 48.3 & 46.9 \\
\hline Banking & 35.2 & 33.8 & 31.2 & 29.7 & 29.3 & 27.9 \\
\hline Calculator Using & 19 & 18.1 & 17.1 & 16.3 & 15.2 & 14.6 \\
\hline Calendar Use & 44.1 & 42.3 & 41.3 & 39.6 & 42.5 & 40.2 \\
\hline Holy Quran & 25.3 & 27.3 & 26.3 & 26.9 & 22.8 & 26.7 \\
\hline WhatsApp & 108.5 & 99.3 & 95.3 & 99.2 & 103.3 & 105.3 \\
\hline Twitter & 99.1 & 102.3 & 93.5 & 99.3 & 100.2 & 99.3 \\
\hline YouTube & 99.4 & 104.8 & 96.5 & 97.3 & 98.5 & 97.9 \\
\hline Souq Application & 37.2 & 45.6 & 32.7 & 43.2 & 38.2 & 40.9 \\
\hline Azan Timing & 10.3 & 7.3 & 8.3 & 9.3 & 7.3 & 7.6 \\
\hline Qibla Direction & 15 & 11 & 17 & 13 & 19.3 & 16.5 \\
\hline Facebook & 90.1 & 99.7 & 87.6 & 92.3 & 90.2 & 93.2 \\
\hline Playing Games & 108.2 & 98 & 98.3 & 99.8 & 102 & 109.4 \\
\hline Instragram & 25.1 & 24.5 & 26.4 & 23 & 21.3 & 19 \\
\hline Weather & 29.1 & 25 & 18.5 & 10.3 & 22.3 & 28 \\
\hline Clock & 25.8 & 20.9 & 21.5 & 23.2 & 19.3 & 22.4 \\
\hline News & 22.3 & 30.3 & 21.9 & 19.4 & 23.2 & 19 \\
\hline
\end{tabular}




\begin{tabular}{|l|c|c|c|c|c|c|}
\hline Google Maps & 78.9 & 90.4 & 99.3 & 89.9 & 21.3 & 25 \\
\hline Shopping & 39.4 & 39.4 & 36.4 & 36.3 & 38.4 & 32.4 \\
\hline Live Sports & 98.2 & 102.3 & 93.6 & 97.3 & 67.9 & 78 \\
\hline Transport Application & 33.3 & 32 & 31.9 & 36.3 & 23.3 & 28.7 \\
\hline Other Apps & 41.2 & 46.7 & 39.6 & 45.6 & 40.9 & 40.3 \\
\hline
\end{tabular}

Table above displays the amount of time utilized on each of the smartphone activity. The analysis of the survey indicates that the participants spend most time on WhatsApp application (108 min), twitter, (99 min), Live sport (98.2 min), Google maps (78.9 min), Internet surfing (55.5 min) and Facebook $(90.1 \mathrm{~min})$. The analyses of gender differences on the smartphone activities show that female participants tend to spend more time ( 99 min per day as compared to male 93 min on sending and receiving SMS) on certain applications except sport and Transportation application (male $33.3 \mathrm{~min}$ and female 23.3). About more than 25\% of Population spend time on making calls and SMS every day.

Table 2. Smartphone Addiction

\begin{tabular}{|l|c|c|c|}
\hline \multicolumn{1}{|c|}{ Items } & Total & Male & Females \\
\hline I get restless when my phone is out of my sight. & 0.85 & 0.75 & 0.87 \\
\hline I get anxious when my smart phone's battery is low. & 0.79 & 0.74 & 0.76 \\
\hline I devote more time than I am currently spending. & 0.88 & 0.78 & 0.84 \\
\hline I am spending more time on my smartphone. & 0.81 & 0.83 & 0.80 \\
\hline \multicolumn{4}{|c|}{ Indices } \\
\hline Df & 3 & 3 & 3 \\
\hline$A$ & 0.86 & 0.83 & 0.89 \\
\hline$x^{2}$ & 17.81 & 9.76 & 11.99 \\
\hline
\end{tabular}

Table 2 displays the mobile phone addiction of the participants' lodges. To authenticate the smartphone addiction, single factor dimension that was consisted four items was calculated independently on whole population sample and the two subordinated sections (male and female). It is vital form the results analysis that $(\mathrm{df}=2)$ remained constant which is an indication of the the measurement of the selected sample is satisfactory. Moreover, the value of Cornbach alpha is greater than the .7 that is $(0.86$; $0.83 ; 0.89)$ respectively which is an indication of the internal consistency of the paradigm. The data analysis indicated that above $90 \%$ participant were curious about their smartphone. It was difficult for them to spent time without their smartphone.

\subsection{Smartphone addiction for learning}

Another important concern of the present attempt was to investigate learners' smartphone addiction relation to academic purposes. For this reason research developed five-point Likert scale to examine the participants' the use of smartphone for the learning purposes. They were asked to mark their most relevant aspect of smartphone with their mobile phone activities. Table 3 displays participants' perceptions on the use smartphone for learning purposes. 
Table 3. Participants' perceptions on the use smartphone for learning

\begin{tabular}{|l|c|c|c|c|c|}
\hline \multicolumn{1}{|c|}{ Smartphone usage } & SD & D & N & A & SA \\
\hline I often use my smartphones for learning purposes & $19.6 \%$ & $21.6 \%$ & $31.5 \%$ & $18.6 \%$ & $8.7 \%$ \\
\hline Smartphone can assist my learning & $8.7 \%$ & $18.9 \%$ & $35.5 \%$ & $31.5 \%$ & $7.5 \%$ \\
\hline SMS and Calls may have impact in my learning ability & $22.7 \%$ & $24.8 \%$ & $29.3 \%$ & $14.3 \%$ & $6.8 \%$ \\
\hline I Use my smartphone during my class for discussion & $12.3 \%$ & $19.4 \%$ & $35.8 \%$ & $22.6 \%$ & $9.8 \%$ \\
\hline Smartphone is a medium of interaction with the teacher & $7.6 \%$ & $11.4 \%$ & $21.0 \%$ & $39.5 \%$ & $20.6 \%$ \\
\hline Smartphone has the ability to foster my learning & $10.3 \%$ & $11.2 \%$ & 12.55 & $16.1 \%$ & $49.7 \%$ \\
\hline Teachers should use smartphone for learning in class & $5.7 \%$ & $5.6 \%$ & $10.7 \%$ & $46.1 \%$ & $38.2 \%$ \\
\hline I use learning applications through my smartphone & $19.8 \%$ & $27.7 \%$ & $17.8 \%$ & $10.3 \%$ & $16.4 \%$ \\
\hline Smartphone is source of distraction in the class & $10.0 \%$ & $10.2 \%$ & $25.9 \%$ & $22.4 \%$ & $41.4 \%$ \\
\hline Smartphone usage is wastage of time when it is used in the class & $7.8 \%$ & $12.9 \%$ & $41.0 \%$ & 15.1 & $20.3 \%$ \\
\hline
\end{tabular}

It is vivid from table 3 that most of the participants acknowledged the usefulness of the smartphone activities. Research has indicted the positive findings on the use of technology particularly m-learning for the learning. Though, the data analysis shows that participant didn't use (31\% neutral; 18.6 Agree and $8.8 \%$ strongly agree) smartphone to foster their learning process but they have the awareness of the smartphone benefits of the learning pursuits. A majority of the participants have indicated $(\mathrm{N}=39.5 \%$ Agree, $\mathrm{N}=20.6 \%$ strongly agree) that smartphones can facilitate the teacher and student interaction for the purpose of learning, sending and receiving information. Similarly, the participants of the present attempt also exhibited positive perceptions of the teachers' integration of smartphones notion for the learning purposes. A huge number of proposition ( $\mathrm{N}=46.1 \%$ Agree, $\mathrm{N}=38.2 \%$ strongly agree) desired that teachers should use smartphones for the learning purposes. However, participants of the survey $(\mathrm{N}=22.4 \%$ Agree, $\mathrm{N}=41.4)$ strongly agree) also marked that the use of smartphones can lead to distract the process of learning. This assertion is the contradiction on the usefulness of smartphones addiction for the learning purposes.

\section{Discussion}

Taking into consideration of the increased amount of time consumed by using technology may have the possibly destructive effects on the life of students. The current attempt of the smartphone addiction' investigation is essentially important. Shambare \& Zhowa, (2012) assert that smartphone usage is "possibly the biggest nondrug addiction of the 21st century;" In Saudi context the present attempt is one for the few studies that investigated the smartphone activities are considerably linked with smartphone addiction. The results of the present study indicate that female participants tend to spend more time on the smartphone usage daily. Contrary to this usage there is very little time spent on the use of smartphone activities for learning purposes.

The findings of the present study are in the line with the study of (Junco and Cotton 2012) found that the college students consume more time (420 min) every day on the utilization of ICT. The present study also found that the university study consumed more time on smartphone activities. Sometimes the university students come to class with having not enough sleep and they cannot concentrate in the class (personal ob- 
servation of the researcher). This observation also strengthens the findings of the study. Moreover, a previous investigation for example (Hakoama, 2011) asserts that females have more tendency and intense connection to their phones as compared to the males. The present study has also similar findings.

The present study endorsed that like other parts of the world Saudi Learners are also addicted to the smartphones. The most famous applications or activities were the use of WhatsApp, Twitter and Sports application. More than $81 \%$ of the participants are use above mentioned social media applications in their daily lives. The analysis of the data indicated showed that participants' do not turn off their cell phone during even if they are asleep. This confirmed the addiction of the smartphones. Smartphones are the important element of the Saudi population. The addiction analysis indicted that the participant will become stressed or annoyed if they are asked to leave their mobile phone for a while. They were anxious about the battery of their smartphone. Over $80 \%$ of the addiction was for the non-academic purposes. They check their smartphone even several times even if they are in the classroom.

\section{$7 \quad$ Implications}

Smartphones are useful for the academic purposes to share the information among the classmates and instructors (Khan et al. 2018). Learners can use this captivating and attractive gadget to facilitate their learning process in improved and better way. To this end about $65 \%$ of the participants indicated that smartphone should be used by the teacher in the class. In addition $82 \%$ of the participants indicted that smartphones are the source of interaction. However, for some participants smartphone addiction for learning purposes is just a waste of time and effort.

Smartphones are an important element of human being's daily life as well as the students' life and culture. The present attempt indicates that university students consume nearly more than eight hours on their smartphones. As the operational use of smartphones is continuously expanding, the addiction to the smartphones is apparently essential element of daily life. Some activities on the smartphones are essential part of the life and hence this addiction is common. The results of the study also suggest that this addiction can be effectively and purposefully used for the development of student learning performance in different field of the study. As suggested in the literature review part that teachers need a careful planning for using this addiction to a useful purpose. Another important aspect that the present attempt revealed is that smartphones are useful for the leaning but learners have a tendency to use them for non-academic purposes. The curriculum planners and higher institutions can yield the potential benefits of the smartphones to capitalize the learning process. The results of the present study also exhibit that smartphone application designer must keep positive aspect into account on its usage for learning purpose. The ubiquitous presence of smartphones presents a variety of options for the students. Smartphone addiction can be definitely used purposefully for the classroom interaction in academia. 


\section{$8 \quad$ Recommendation and Limitations}

Though the present attempt was among very few in the Saudi Arabia to examine the smartphone linked activities which included gender comparison but still it must be strengthened by considering its limitation. There is a need of random sampling as the sample in the present attempt was not selected randomly. Furthermore, there is a need of an explanatory study to include different universities to reach at the definite findings. Moreover the study is quantitative in nature and it was found in the data analysis that some learners need explanation of the items of the usefulness of the Smartphone addiction so; participants' interviews are operative for more useful results.

\section{$9 \quad$ References}

[1] Ahmed, I., Qazi, T. F., and Perji, K. A. 2011. "Mobile Phone to Youngsters: Necessity or Addiction," Information Management and Business Review (2:5), pp. 229-238.

[2] Alshehri, H., \& Meziane, F. (2017). Current state on internet growth and usage in Saudi Arabia and its ability to support e-commerce development. Journal of Advanced Management Science, 5(2), 127-132. https://doi.org/10.18178/joams.5.2.127-132

[3] Bright, L., Grau, S. L., and Kleiser, S. B. 2015. "Thumbs Down to Facebook? Exploring Social Media Addiction among Millennials Using the Consumption Continuum Framework," American Academy of Advertising Conference Proceedings), pp. 170-171.

[4] Chen, L., and Nath, R. 2016. "Understanding the Underlying Factors of Internet Addiction across Cultures: A Comparison Study," Electronic Commerce Research \& Applications (17), pp. 38-48. https://doi.org/10.1016/i.elerap.2016.02.003

[5] Comer, D. E. (2018). The Internet book: everything you need to know about computer networking and how the Internet works. Chapman and Hall/CRC.Education, 59, 505-514. https://doi.org/10.1201/9780429447358

[6] Elhai, J. D., Levine, J. C., Dvorak, R. D., \& Hall, B. J. (2017). Non-social features of smartphone use are most related to depression, anxiety and problematic smartphone use. Computers in Human Behavior, 69, 75-82. https://doi.org/10.1016/j.chb.2016.12.023

[7] Hakoama, M. \& Hakoyama, S. (2011). The impact of cell phone use on social networking and development among college students. The American Association of Behavioral and Social Sciences Journal, 15, 1-20.

[8] Junco, R. \& Cotton, S. R. (2012). No A 4 U: The relationship between multitasking and academic performance.

[9] Junco, R. (2015). Student class standing, Facebook use, and academic performance. Journal of Applied Developmental Psychology, 36, 18-29. https://doi.org/10.1016/j.appdev.20 $\underline{14.11 .001}$

[10] Kalogiannakis, M., \& Papadakis, S. (2019). Evaluating pre-service kindergarten teachers' intention to adopt and use tablets into teaching practice for natural sciences. International Journal of Mobile Learning and Organisation, 13(1), 113-127. https://doi.org/10.1504/ijm $\underline{10.2019 .10016617}$

[11] Kapahi, A., Ling, C. S., Ramadass, S., and Abdullah, N. 2013. "Internet Addiction in Malaysia Causes and Effects," I - Business (5:2), pp. 72-76. https://doi.org/10.4236/ib.2013.52 $\underline{009}$ 
[12] Khan, R. M. I., Radzuan, N. R. M., Shahbaz, M., \& Ibrahim, A. H. (2018). EFL Instructors' Perceptions on the Integration and Implementation of MALL in EFL Classes. International Journal of Language Education and Applied Linguistics, 39-50.

[13] Khan, R. M.I., Radzuan, N. R. M., Shahbaz, M., Ibrahim, A.H., \& Ghulam Mustafa (2018). The Role of Vocabulary Knowledge in Speaking Development of Saudi EFL Learners. Arab World English Journal, 9 (1). https://doi.org/10.24093/awej/vol9no1.28.

[14] Khan, R. M. I., Radzuan, N. R. M., Alkhunaizan, A. S., Mustafa, G., \& Khan, I. (2019). The Efficacy of MALL Instruction in Business English Learning. International Journal of Interactive Mobile Technologies, 13(8). https://doi.org/10.3991/ijim.v13i08.9562

[15] Kim, D., Lee, Y., Lee, J., Nam, J. K., \& Chung, Y. (2014). Development of Korean smart phone addiction proneness scale for youth. PloS one, 9(5), e97920. https://doi.org/10.1371/ journal.pone.0097920

[16] Lai, K. W., \& Hong, K. S. (2015). Technology use and learning characteristics of students in higher education: Do generational differences exist? British Journal of Educational Technology, 46(4), 725-738. http://saudigazette.com.sa/article/558395 https://doi.org/10.1 $111 /$ bjet.12161

[17] Müller, K. W., Dreier, M., Beutel, M. E., Duven, E., Giralt, S., \& Wölfling, K. (2016). A hidden type of internet addiction? Intense and addictive use of social networking sites in adolescents. Computers in Human Behavior, 55, 172-177. https://doi.org/10.1016/j.chb.20 15.09 .007

[18] Papadakis, S. (2018). Evaluating pre-service teachers' acceptance of mobile devices with regards to their age and gender: a case study in Greece. IJMLO, 12(4), 336-352. https:// doi.org/10.1504/ijmlo.2018.10013372

[19] Papadakis, S., \& Kalogiannakis, M. (2017). Mobile educational applications for children: what educators and parents need to know? International Journal of Mobile Learning and Organisation, 11(3), 256-277. https://doi.org/10.1504/ijmlo.2017.085338

[20] Papadakis, S., Kalogiannakis, M., Sifaki, E., \& Vidakis, N. (2017). Access moodle using smart mobile phones. A case study in a Greek University. In Interactivity, Game Creation, Design, Learning, and Innovation (pp. 376-385). Springer, Cham. https://doi.org/10.1007/9 78-3-319-76908-0 36

[21] Postman, N. (2011). Technopoly: The surrender of culture to technology. Vintage.

[22] Shahbaz, M., \& Khan, R. M. I. (2017). Use of mobile immersion in foreign language teaching to enhance target language vocabulary learning. MIER Journal of Educational Studies, Trends and Practices, 7(1).

[23] Shambare, R., Rugimbana, R., \& Zhowa, T. (2012). Are mobile phones the 21 st century addiction? African Journal of Business Management, 6(2), 573-577.

[24] Shiau, W., \& George, J. F. (2014). A Grounded Theory Approach to Information Technology Adoption. Communications of the Association for Information Systems, 34, pp-pp. https://doi.org/10.17705/1 cais.03481

[25] Wang, D., Xiang, Z., \& Fesenmaier, D. R. (2016). Smartphone use in everyday life and travel. Journal of travel research, 55(1), 52-63. https://doi.org/10.1177/0047287514535847

[26] Wang, L., Luo, J., Bai, Y., Kong, J., Luo, J., GAO, W., \& Sun, X. (2013). Internet addiction of adolescents in China: Prevalence, predictors, and association with well-being. Addiction Research \& Theory, 21(1), 62-69. https://doi.org/10.3109/16066359.2012.690053

[27] Weinstein, A., Dorani, D., Elhadif, R., Bukovza, Y., Yarmulnik, A., \& Dannon, P. (2015). Internet addiction is associated with social anxiety in young adults. Annals of Clinical Psychiatry, 27(1), 4-9. 


\section{Author}

Dr. Abdul Mohsin Alkhunaizan is currently serving as an Assistant Professor at Department of computer science, Majma'ah University. He holds a PhD degree from UK and more than 5 years of research Experience. His research interests include ELearning; E-Commerce and Information Technology.

Article submitted 2019-06-25. Resubmitted 2019-09-05. Final acceptance 2019-09-05. Final version published as submitted by the authors. 